\title{
Japan's new international superconductivity centre opens
}

\section{Tokyo}

JAPAN's International Superconductivity Technology Center, set up with massive funds from the private sector at the urging of the Ministry of International Trade and Industry (MITI) opens today (14 January). Foreign (that is, non-Japanese) companies are welcome to join - but at a price.

A committee of academics and industrialists formed by MITI in response to the explosion of interest in the new hightemperature superconductors recommended the establishment of the centre in a report released last September. The centre will both gather and disseminate information and establish a laboratory for research (see Nature, 330, 2; 1987).

More than fifty companies, including electric utility, electronic and cable manufacturing companies, mining concerns, a gas corporation, steel and glass producers, shipbuilders, car manufacturers, even spark-plug producers and banks have signed up to join the information centre, membership of which requires a downpayment of $¥ 2$ million (about $\$ 16,000$ ) plus an annual subscription of the same amount.

The centre will hold international symposia, seminars and workshops, gather and disseminate information in a newsletter, invite foreign researchers to give lectures in Japan and also carry out public education campaigns.

But the budget for the information centre is nothing compared with the funds going to the research laboratory. About 40 companies will donate $¥ 100$ million each to set up the laboratory and $¥ 12$ million a year for running costs, over and above the donations for information. This brings the total budget for the centre to about $¥ 4,700$ million (nearly $\$ 40$ million) in its first year of operation.

The laboratory will open in October this year on a site in Tokyo rented from the Tokyo Gas Corporation, one of the founding members. There will be five research laboratories covering oxide and non-oxide research, processing technology, physical property evaluation and research into the theory. A research laboratory in Nagoya will also carry out research on ceramics.

The companies that join the laboratory can send one or two researchers. And they can also have members on the board, the decision-making body of the centre. Rights to patents resulting from research will be shared by the centre and the company of the researcher that makes the discovery. And, according to MITI officials, foreign companies are welcome to join, provided they pay the fee. The centre may also employ its own researchers, including foreigners, in addition to those from the companies.

MITI is also studying the possibility of inviting researchers to the laboratory from foreign public research institutions. But, realizing that the membership fee may be beyond the reach of such organizations, MITI will adopt a 'flexible' approach when determining the participation fees when the need arises.

MITI has already contacted several US and European companies, and brochures in English have been sent to the US Chamber of Commerce. MITI is now hunting for a suitable European organization to which to send pamphlets. But, according to Risaburo Nezu, of MITI's Agency of Industrial Science and Technology, it is difficult to decide whom to send pamphlets to as "there are so many countries". Suggestions would be welcome, he says.

MITI is clearly keen to make the centre international to help diffuse US criticisms that Japan has not been making a fair contribution to international basic research (a criticism which even Japanese government officials widely accept). And while some in the United States and Europe may suspect MITI's intentions (is it another plot to steal ideas from the West?), the ministry is obviously striving to establish a truly international research centre. And, judging from the rapid rate of developments in this field in Japan (for

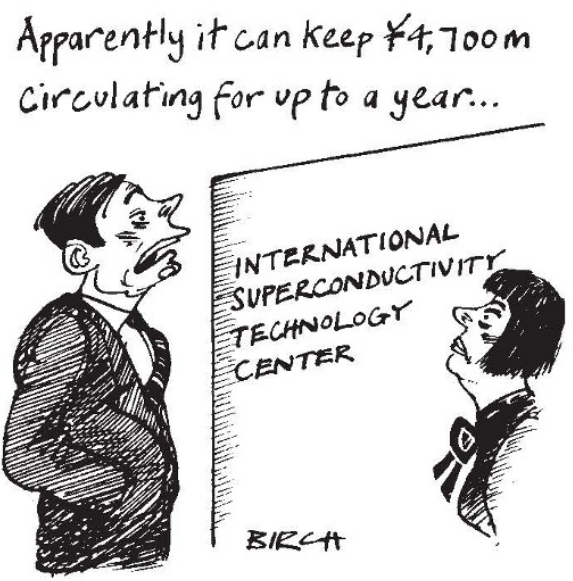

example, see article below) foreign countries may be well advised to take advantage of the opportunity to join.

David Swinbanks

\section{Another breakthrough for Japan in superconductor technology}

\section{Tokyo}

Just when all seemed quiet on the hightemperature superconductor front, Japan has announced another 'breakthrough'. Researchers at Sumitomo Electric Indus-

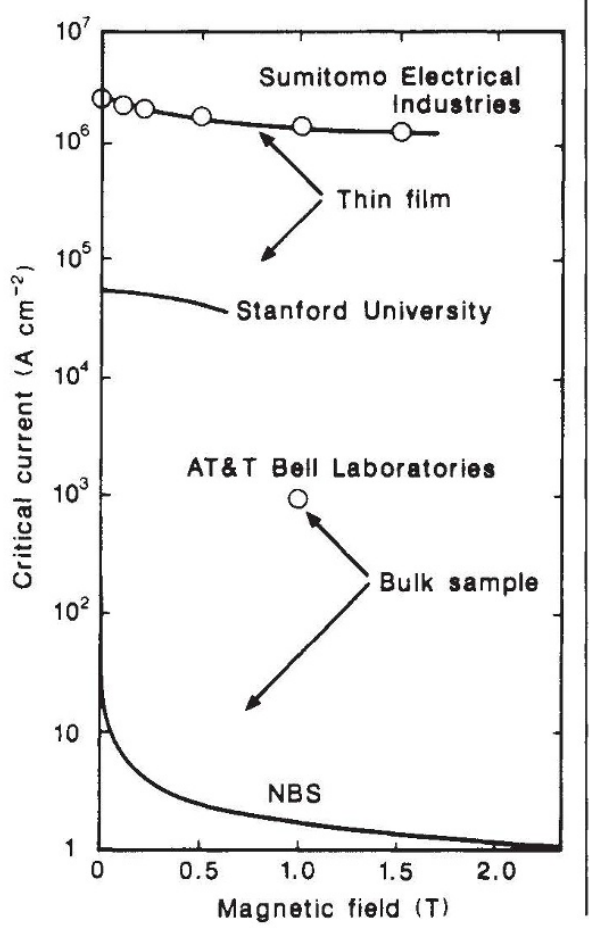

tries have developed a single-crystal thin film that can carry a maximum current of 2.5 million $\mathrm{A} \mathrm{cm}^{-2}$ at the temperature of liquid nitrogen; high current-carrying capacity is also maintained in a strong magnetic field.

The development, announced last week (6 January) breaks the previous record set by Nippon Telegraph and Telephone (NTT) (1.8 million A $\mathrm{cm}^{-2}$ in July last week (Nature 329, 98; 1987), and the technique to make the film differs from that of NTT.

Holmium-barium-copper oxide was sputtered epitaxially on the $\langle 100\rangle$ crystal face of a monocrystal MgO substrate (as opposed to the $\langle 110\rangle$ face of a $\mathrm{SrTiO}_{3}$ substrate in the case of NTT). As a result, the $a$ and $b$ crystal axes of the ceramic lie perpendicular and parallel respectively, to the plane of the film and high currentcarrying capacity is thus possible in both the vertical and horizontal directions in the film.

One major problem besetting the development of the new high- $T_{\mathrm{c}}$ superconductors has been their inability to carry high currents under a magnetic field. But Sumitomo's thin film maintains a critical current density of 1.5 million $\mathrm{A} \mathrm{cm}^{-2}$ under a magnetic field of 1 tesla. And the currentcarrying capacity of the film has remained stable for over a month. David Swinbanks 